\title{
Passive sampling of ambient ozone by solid phase microextraction with on-fiber derivatization
}

\author{
I-Su Lee, Shih-Wei Tsai* \\ Institute of Environmental Health, College of Public Health, National Taiwan University, No. 17, Xuzhou Road, Taipei 100, Taiwan
}

\section{A R T I C L E I N F O}

\section{Article history:}

Received 8 November 2007

Received in revised form

14 January 2008

Accepted 15 January 2008

Published on line 19 January 2008

\section{Keywords:}

Ozone

1,2-Di-(4-pyridyl)ethylene

$0-2,3,4,5,6-$

(pentafluorobenzyl)hydroxylamine hydrochloride

Solid phase microextraction

Passive sampler

\begin{abstract}
A B S T R A C T
The solid phase microextraction (SPME) device with the polydimethylsiloxane/divinylbenzene (PDMS/DVB) fiber was used as a passive sampler for ambient ozone. Both 0-2,3,4,5,6-(pentafluorobenzyl)hydroxylamine hydrochloride (PFBHA) and 1,2-di-(4-pyridyl)ethylene (DPE) were loaded onto the fiber before sampling. The SPME fiber assembly was then inserted into a PTFE tubing as a passive sampler. Known concentrations of ozone around the ambient ground level were generated by a calibrated ozone generator. Laboratory validations of the SPME passive sampler with the direct-reading ozone monitor were performed side-by-side in an exposure chamber at $25^{\circ} \mathrm{C}$. After exposures, pyriden4-aldehyde was formed due to the reaction between DPE and ozone. Further on-fiber derivatizations between pyriden-4-aldehyde and PFBHA were followed and the derivatives, oximes, were then determined by portable gas chromatography with electron capture detector. The experimental sampling rate of the SPME ozone passive sampler was found to be $1.10 \times 10^{-4} \mathrm{~cm}^{3} \mathrm{~s}^{-1}$ with detection limit of $58.8 \mu \mathrm{g} \mathrm{m}^{-3} \mathrm{~h}^{-1}$. Field validations with both SPME device and the direct-reading ozone monitor were also performed. The correlations between the results from both methods were found to be consistent with $r=0.9837$. Compared with other methods, the current designed sampler provides a convenient and sensitive tool for the exposure assessments of ozone.
\end{abstract}

(c) 2008 Elsevier B.V. All rights reserved.

\section{Introduction}

Ozone $\left(\mathrm{O}_{3}\right)$ is a colorless, odorless gas and is extremely reactive and toxic. Among various air pollutants, ozone plays an important role due to the characteristics of its occurrence and possible health effects [1]. In ambient air, ozone is attributable to different sources. One is the intrusion of stratospheric ozone, especially in the spring when the stratospheric-tropospheric air exchange is greatest [1]. The other sources are driven by complex photochemical reaction sequences requiring input of organic vapors, nitrogen oxides $\left(\mathrm{NO}_{x}\right)$ and actinic radiation [1]. As an ambient air pollutant, ozone has become a subject of great inter- est because of its effects on both humans and plants [2].

Exposure to ozone is associated with various respiratory symptoms including dyspnea, upper airway irritation, coughing and chest tightness [3], since ozone initiate lung inflammation [4]. Such effects can be observed within the first few hours after the start of the exposure, and may persist for many hours or days after the exposure ceases [1]. Besides the effects mentioned above, headache, asthma and tiredness have also been reported [5]. On the other hand, chronic exposure to ozone will reduce lung function [6,7], while the alteration of semen quality due to the exposure of ozone was observed as well [8].

\footnotetext{
* Corresponding author. Tel.: +886 23322 8097; fax: +886 223516289.

E-mail address: shihweitsai@ntu.edu.tw (S.-W. Tsai). 
The ambient ozone levels in the United States have generally declined since the enactment of the Clean Air Act in 1970. However, high ozone concentrations persist with many areas still having levels above the health-based National Ambient Air Quality Standards (NAAQS) [9]. It was estimated that over 100 million people in the US resided in areas with ozone concentrations exceeding the 8-h regulatory USEPA standard [10]. In Europe, ambient ozone is the most important regional air pollutant as well. It was reported that in rural areas of Europe, the overall average AOT40 (accumulated dose over a threshold of $78.4 \mu \mathrm{g} \mathrm{m}^{-3}$ ) value has still shown a tendency to increase [11].

Continuous monitors are often used to measure ozone concentrations in National Air Quality Network. However, these monitors are costly and mostly concentrated in urban or suburban areas which make it difficult to infer the ozone spatial pattern [12]. On the other hand, there are many situations where time-integrated measurements of ozone are more useful than short-term measurement, e.g., regulatory-driven assessment of ozone dose and exposure for environmental health, forest damage, agricultural crop damage, regional air quality and ecosystem studies [13]. Therefore passive samplers which offer a simple, cost-effective means of measuring air pollutants have been performed for the monitoring of ambient ozone levels worldwide [2,5,12,13].

Several methods have been developed to determine ambient ozone by passive sampling while various sampling reagents were used, including 1,2-di-(4-pyridyl)ethylene (DPE) $[2,14,15]$, indigo carmine $[13,15-17]$, potassium iodide $[15,18]$ and nitrite ion $[16,17,19]$. However, there were drawbacks of the methods mentioned above. For example, the sampling time needed for current methods was relatively long due to the limited sensitivities, since either spectrophotometer or ion chromatography was used as the analytical instrument for most of the currently available ozone passive samplers. Besides, organic solvents were usually used for the sample desorption and the process was relatively time-consuming.

As mentioned before, the determination of ambient ozone can be performed by the reaction with DPE while ozonide formed undergoes cleavage and yields pyridin-4aldehyde [14]. The reaction has proved to be effective and the aldehyde is finally determined spectrophotometrically by the methyl-benzthioazolinone-hydrazone (MBTH) method at $442 \mathrm{~nm}$ [2]. However, the sampling time needed for the DPE method with the analysis of spectrophotometer was relatively long due to the limited sensitivities. Generally speaking, derivatization techniques with chromatographic approaches can enhance sensitivity as well as selectivity [20]. Since the determinations of aldehydes with great sensitivities can be achieved by the derivatization with O-2,3,4,5,6-(pentafluorobenzyl)hydroxylamine hydrochloride (PFBHA) followed by the analysis with gas chromatography [21-23], lower detection limits for the measurements of ambient ozone might be reached if pyridin-4-aldehyde formed from the reaction between ozone and DPE was further derivatized with PFBHA to form oximes and then analyzed by gas chromatograph (GC).

On the other hand, an extraction technique called solid phase microextraction (SPME) has been developed by Pawliszyn [24,25]. SPME presents many advantages over conventional analytical methods by combining sampling, preconcentration, and direct transfer of the analytes into a standard GC system [26]. There have been many applications of SPME in the environmental field. For example, aldehydes derivatized with PFBHA to form oximes in solutions followed by extraction with SPME from liquid or headspace and analyzed by GC/ECD was reported [21]. Other than water sample, the air sampling and analysis methods with SPME have been applied to both grab and time-weighted average (TWA) modes [26-28]. This approach is superior to currently available diffusive sampling methods in overall analytical sensitivity because all of the sorbed analytes are introduced into the analytical instrument for quantitation rather than a small fraction of the extract [29]. Diffusive sampling using SPME combined with on-fiber derivatization has also been reported [30].

To increase the acceptance of using SPME device as a personal diffusive sampler, a user-friendly SPME sampling device has then been developed elsewhere [22,31,32]. In this research, the modified SPME device was extended to the validation of ozone sampling.

\section{Experimental}

\subsection{Materials}

Pyridin-4-aldehyde, $n$-hexane and 0-2,3,4,5,6-(pentafluorobenzyl)hydroxylamine hydrochloride were purchased from Sigma-Aldrich (Milwaukee, WI, USA). 1,2-Di-(4-pyridyl) ethylene was from Fluka (St. Louis, MO, USA). A Whatman Zero Air generator was from Balston (Haverhill, MA, USA) and was used to provide the air for a standard gas generation system. A M-5 Mini-Buck Calibrator for air flow rate calibrations was from Buck Scientific (East Norwalk, CT, USA). A calibrated hot-wire anemometer used to monitor face velocity was from Kanamox Instrument Co., Japan. Ozone generator used was API Model 401 from Advanced Pollution Instruments (San Diego, CA, USA). All SPME fibers, holders and molecular sieve were from Supelco (Bellefonte, PA, USA). All retracted fiber path length and surface area were measured by inserting a steel tube that had an outer diameter equal to the needle tube inner diameter, then measuring the depth and outer diameter of the inserted tube.

\subsection{Instrumentation}

Hewlett-Packard 6890 gas chromatography equipped with a 5972 mass-selective detector (Agilent Tech, USA) as well as $60 \mathrm{~m} \times 0.25 \mathrm{~mm}$ i.d., $0.25 \mu \mathrm{m}$ film thickness Rtx- 5 column from Restex (Bellefonte, PA, USA) was used to confirm the oximes formed. Injection port temperature was $250^{\circ} \mathrm{C}$ with splitless mode and a $0.75 \mathrm{~mm}$ i.d. SPME injection sleeve liner (Supelco) was used. The temperature program was: $120^{\circ} \mathrm{C}$, increased to $200^{\circ} \mathrm{C}$ at a rate of $10^{\circ} \mathrm{C} \mathrm{min}^{-1}$ and held for $8 \mathrm{~min}$. Helium for GC/MS was $99.9995 \%$ supplied from Sanfu Co., Taiwan. All the work was carried out in constant flow mode set at $1.0 \mathrm{~mL} \mathrm{~min}^{-1}$. Qualitative and quantitative analyses were operated in the selected ion monitoring (SIM) mode.

SRI 8610C portable GC with electron capture detector (SRI Instruments; Torrance, CA, USA) was used for sample deter- 


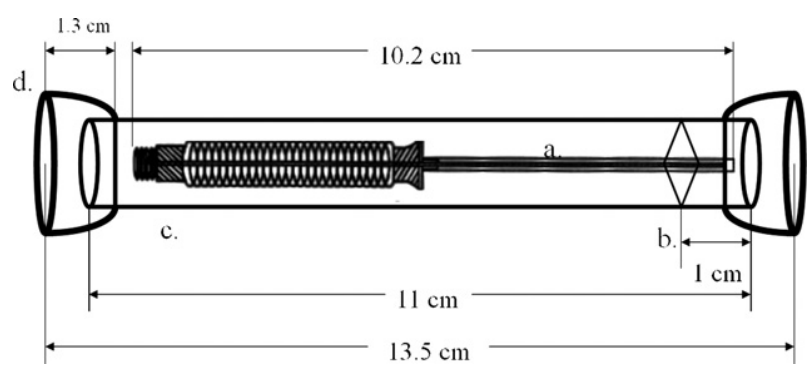

Fig. 1 - Perspective view of the passive sampler: (a) SPME fiber assembly, (b) PTFE septum, (c) PTFE tubing and (d) cap/PTFE tape.

mination. MXT-1 capillary column with $30 \mathrm{~m} \times 0.25 \mathrm{~mm}$ i.d., $0.25 \mu \mathrm{m}$ film thickness was supplied by Restex (Bellefonte, PA, USA). The carrier gas was helium with flow rate of $10 \mathrm{~mL} \mathrm{~min}^{-1}$ while nitrogen with flow rate of $60 \mathrm{~mL} \mathrm{~min}^{-1}$ was used as the makeup gas for the electron capture detector. The temperature for the injector was $270^{\circ} \mathrm{C}$. The column temperature program was: $150-250^{\circ} \mathrm{C}$ at $10^{\circ} \mathrm{C} \mathrm{min}^{-1}$, and held for $15 \mathrm{~min}$.

\subsection{Sampling}

\subsubsection{Theory}

By retracting the coated fiber into its needle housing during the sampling, the SPME device can be used as a TWA diffusive sampler and the theory has been reported elsewhere [25]. Fick's first law of diffusion is used to model steady-state mass transport through the sampler and to determine the amount of analyte loaded on the fiber coating. The sampling rate SR of the sampler can be defined as follows [27]:

$\mathrm{SR}=\mathrm{D}_{\mathrm{AB}}\left(\frac{\mathrm{A}}{\mathrm{Z}}\right)$

where: SR: sampling rate $\left(\mathrm{cm}^{3} \mathrm{~min}^{-1}\right)$; $Z$ : retracted fiber path length $(\mathrm{cm})$; A: surface area of the needle opening $\left(\mathrm{cm}^{2}\right) ; D_{A B}$ : the diffusion coefficient of the analyte in the gaseous phase $\left(\mathrm{cm}^{2} \mathrm{~min}^{-1}\right)$.

As shown in Fig. 1, a modified SPME device was used in this research where the SPME fiber was retracted $3 \mathrm{~mm}$ into its needle housing [22,31,32]. The SPME fiber assembly was inserted into an $11 \mathrm{~cm}$ length PTFE tubing $(0.48 \mathrm{~cm}$ i.d. $\times 0.64 \mathrm{~cm}$ o.d.). The needle was fixed by a PTFE septum and the tubing was capped by two caps lined with PTFE tape to avoid contamination.

The cap near the needle, as shown in Fig. 1, was opened during sampling. Afterwards, the cap was closed again and the samples were stored in a refrigerator. The fiber assembly in the PTFE tubing was removed and assembled with the SPME holder right before further sample analysis was performed.

During sampling, the fiber was retracted $0.3 \mathrm{~cm}(Z=0.3 \mathrm{~cm})$ while surface area of the needle opening was $0.00086 \mathrm{~cm}^{2}$ [27]. Diffusion coefficient of ozone in air can be estimated by the following equation [33]:

$D_{A B}=\frac{0.00143 \times T^{1.75}}{\operatorname{PM}_{A B}^{1 / 2}\left[\left(\sum_{V}\right)_{A}^{1 / 3}+\left(\sum_{V}\right)_{B}^{1 / 3}\right]^{2}}$ where: $D_{A B}$ is the binary diffusion coefficient of analyte in air in $\mathrm{cm}^{2} \mathrm{~s}^{-1}$ at $\mathrm{T}$; $\mathrm{T}$ is temperature $(\mathrm{K}) ; \mathrm{M}_{\mathrm{A}}$ and $\mathrm{M}_{\mathrm{B}}$ are molecular weight $\left(\mathrm{g} \mathrm{mol}^{-1}\right) ; \mathrm{M}_{\mathrm{AB}}=2\left[\left(1 / \mathrm{M}_{\mathrm{A}}\right)+\left(1 / \mathrm{M}_{\mathrm{B}}\right)\right]^{-1} ; P$ is the external pressure (bar); $\Sigma_{V}$ is the summation of atomic diffusion volumes (unitless); $i$ is all the contributing species; A is air; B is the analyte.

Therefore diffusion coefficient for ozone in air at $25^{\circ} \mathrm{C}$ and $1 \mathrm{~atm}$ was $0.177 \mathrm{~cm}^{2} \mathrm{~s}^{-1}$, theoretically. The sampling rate SR of the sampler for ozone was then estimated to be $5.07 \times 10^{-4} \mathrm{~cm}^{3} \mathrm{~s}^{-1}\left(3.04 \times 10^{-2} \mathrm{~cm}^{3} \mathrm{~min}^{-1}\right)$.

\subsubsection{Trapping element of the SPME diffusive sampler}

Five different kinds of SPME fibers including polydimethylsiloxane (PDMS), polydimethylsiloxane/divinylbenzene (PDMS/DVB), carboxen/polydimethylsiloxane (CAR/PDMS), carbowax/divinylbenzene (CW/DVB) and divinylbenzene/carboxen/PDMS (DVB/CAR/PDMS) were examined to establish one that would provide the highest loading and stability of DPE, PFBHA and oxime retention characteristics. For trapping element preparation, $2 \mathrm{~mL}$ of DPE solution $\left(0.2 \mathrm{mg} \mathrm{mL}^{-1}\right)$ was placed in a $4 \mathrm{~mL}$ PTFE-capped vials with a $1 \mathrm{~cm}$ stir bar. The solution was heated to $90^{\circ} \mathrm{C}$ with stirring rate of $1100 \mathrm{rpm}$. The SPME fiber was then inserted into the DPE solution for $30 \mathrm{~s}$ by direct immersion. After loading with DPE, the SPME fiber was retracted $3 \mathrm{~mm}$ into its needle housing and the designed passive sampler was then assembled as mentioned above. After the exposures of ozone, the SPME fiber was inserted into another $4 \mathrm{~mL}$ PTFE-capped vial which was filled with $2 \mathrm{~mL}$ of $17 \mathrm{mg} \mathrm{mL}^{-1}$ PFBHA solution and stirred at $1100 \mathrm{rpm}$. To estimate the amount of pyridine-4-aldehyde formed on-fiber, the SPME fibers were exposed to the PFBHA vapors of the aqueous for 1, 5, 10, 20 and $30 \mathrm{~min}$, respectively. Chromatographic peak areas and calibration curves were used for adsorbed oxime quantification. To ensure the desorption was complete when the SPME needle was inserted into the heated GC injector, different desorption times were tested to examine the desorption efficiencies.

Other than the procedure mentioned above, coating of PFBHA (headspace extraction of $17 \mathrm{mg} \mathrm{mL}^{-1}$ PFBHA solution for $1 \mathrm{~min}$ ) onto the fiber for the preparation of trapping element followed by the direct immersion of DPE solution $\left(0.2 \mathrm{mg} \mathrm{mL}^{-1}\right.$ for $\left.30 \mathrm{~s}\right)$ was also performed in the study. Further validations by the exposures of ozone at different concentrations for various periods of time were followed as well.

\subsection{Validations}

\subsubsection{Laboratory validations}

Two different vapor exposure systems can be used to validate the designed SPME diffusive sampler [32]. One was the air bag method which allowed direct inserting of the SPME fiber. The other one is dynamic vapor generation system. However, the air bag method is not suitable in this study because the half time of ozone is about 20-50 min [34], and the concentration of ozone will decrease in the air bag shortly. Therefore a dynamic gas generation system, as shown in Fig. 2, was used in this research. For ozone generation, the calibrated API Model 401 ozone generator was used.

The SPME device and the continuous ozone analyzer (Aeroqual Series 500 from Aeroqual Ltd.; Auckland, New Zealand) 


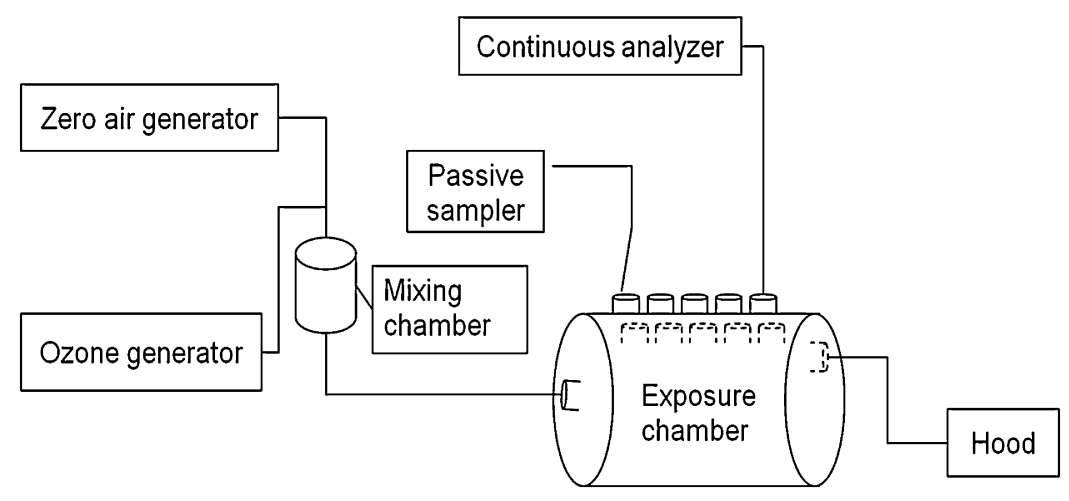

Fig. 2 - Ozone generation and exposure system.

were put in the dynamic gas generation system simultaneously. The exposure chamber was made by a glass cylindrical vessel $(45 \mathrm{~cm} \times 18 \mathrm{~cm}$ i.d. $\times 19 \mathrm{~cm}$ o.d.) and a fan was connected to a variac which allowed different fan blade velocities and hence face velocities, as well as adequate mixing. Ozone concentrations ranged from 39.2 to $784.3 \mu \mathrm{g} \mathrm{m}^{-3}$ were generated by the API Model 401 while different time periods of exposures ranged from $5 \mathrm{~min}$ to $4 \mathrm{~h}$ were performed. For each test, four SPME diffusive samplers were inserted into the chamber simultaneously and the ozone concentrations in the chamber were monitored by the Aeroqual Series 500 as well.

\subsubsection{Field validations}

The behavior of the designed SPME diffusive sampler in the real environment was also validated in the study. Three fulltime mail carriers who used motorcycles to deliver mails daily from the post office of Xinzhuang City, Taipei County, Taiwan, were selected to monitor their daily ozone exposures. The side-by-side comparisons for the working hours per day between the SPME device and the Aeroqual Series 500 Ozone Monitor were performed for three successive days. Temperatures and relative humidities were also measured during the sampling. For each day, the SPME samples were put in a cooler after sampling, shipped back to the laboratory, and stored in a refrigerator before analysis.

\subsection{Synthesis of PFBHA-pyridin-4-aldehyde oxime and standard solutions in hexane}

The oxime formed from the reaction between PFBHA and pyridin-4-aldehyde was synthesized using a modified literature method [35]. Standard PFBHA-pyridin-4-aldehyde oxime solutions $\left(0.005-0.5 \mathrm{ng} \mu \mathrm{L}^{-1}\right)$ were then prepared for GC/MS calibration. Instrumental detection limit (defined as the amount of analyte giving seven times the background response) was determined to be $3.4 \times 10^{-6} \mu \mathrm{g}$.

\section{Results and discussion}

For all the fibers tested in this research (including PDMS, PDMS/DVB, CAR/PDMS, CW/DVB and DVB/CAR/PDMS), oximes and DPE were both detected after the fibers were first headspace exposed to $5 \mathrm{mg} \mathrm{mL}^{-1}$ of pyridine-4-aldehyde for
$1 \mathrm{~min}$, followed by the headspace extraction of PFBHA solution, and finally headspace exposed to $0.2 \mathrm{mg} \mathrm{mL}^{-1}$ of DPE solution for $30 \mathrm{~min}$. As shown in Table 1, PDMS/DVB fiber was selected for further evaluation because it provided the highest sensitivity among all the fibers tested. After the selection of fiber, the condition for thermal desorption was then determined. The desorption efficiency was found to be $100 \%$ when the desorption time was $7 \mathrm{~min}$.

GC/MS was used to identify the oximes which were formed on the fiber after the exposures of ozone. Fig. 3 showed a typical chromatogram of a sample from the SPME direct injection with total ion count (TIC) mode between m/z 100 and 450. It was observed that there were syn and anti isomers of the oxime because pyridine-4-aldehyde was an asymmertrical carbonyl compound. Further confirmation was performed by the injection of standard oxime solutions. It was observed that the retention time of the peaks as well as the mass spectrums from both sample and standards injections were identical. On the other hand, GC-ECD was used in this study for sample quantification since it has been reported to be a sensitive instrument for the analysis of both PFBHA and oxime [21].

As mentioned above, two different procedures for trapping element preparations were performed followed by the similar exposures of ozone in this study. Different concentrations of ozone were generated into the exposure chamber and

Table 1 - Loading abilities of fibers for oximes and DPE

\begin{tabular}{lll} 
Fiber types & \multicolumn{2}{c}{ Relative peak areas $^{\mathrm{a}}$} \\
\cline { 2 - 3 } & Oximes $^{\mathrm{b}}$ & \multicolumn{1}{c}{ DPE $^{\mathrm{c}}$} \\
\hline PDMS & 455,475 & n.d. \\
PDMS/DVB & $1,125,855$ & $8,852,208$ \\
CAR/PDMS & n.d. & n.d. \\
CW/DVB & 110,338 & n.d. \\
DVB/CAR/PDMS & $1,168,172$ & 872,430
\end{tabular}

a All peak areas were shown as mean with $n=3$ and C.V. $<10 \%$; GC/MS was used for the analysis.

b Oximes were formed on-fiber after pyridin-4-aldehyde $\left(5 \mathrm{mg} \mathrm{mL}^{-1}\right)$ was first loaded onto the fiber by headspace extraction for $5 \mathrm{~min}$, followed by the reaction with PFBHA (headspace extraction for $20 \mathrm{~min}$ with PFBHA solution of $17 \mathrm{mg} \mathrm{mL}^{-1}$ ). Headspace extraction of $0.2 \mathrm{mg} \mathrm{mL}^{-1}$ DPE solution for $30 \mathrm{~min}$. 


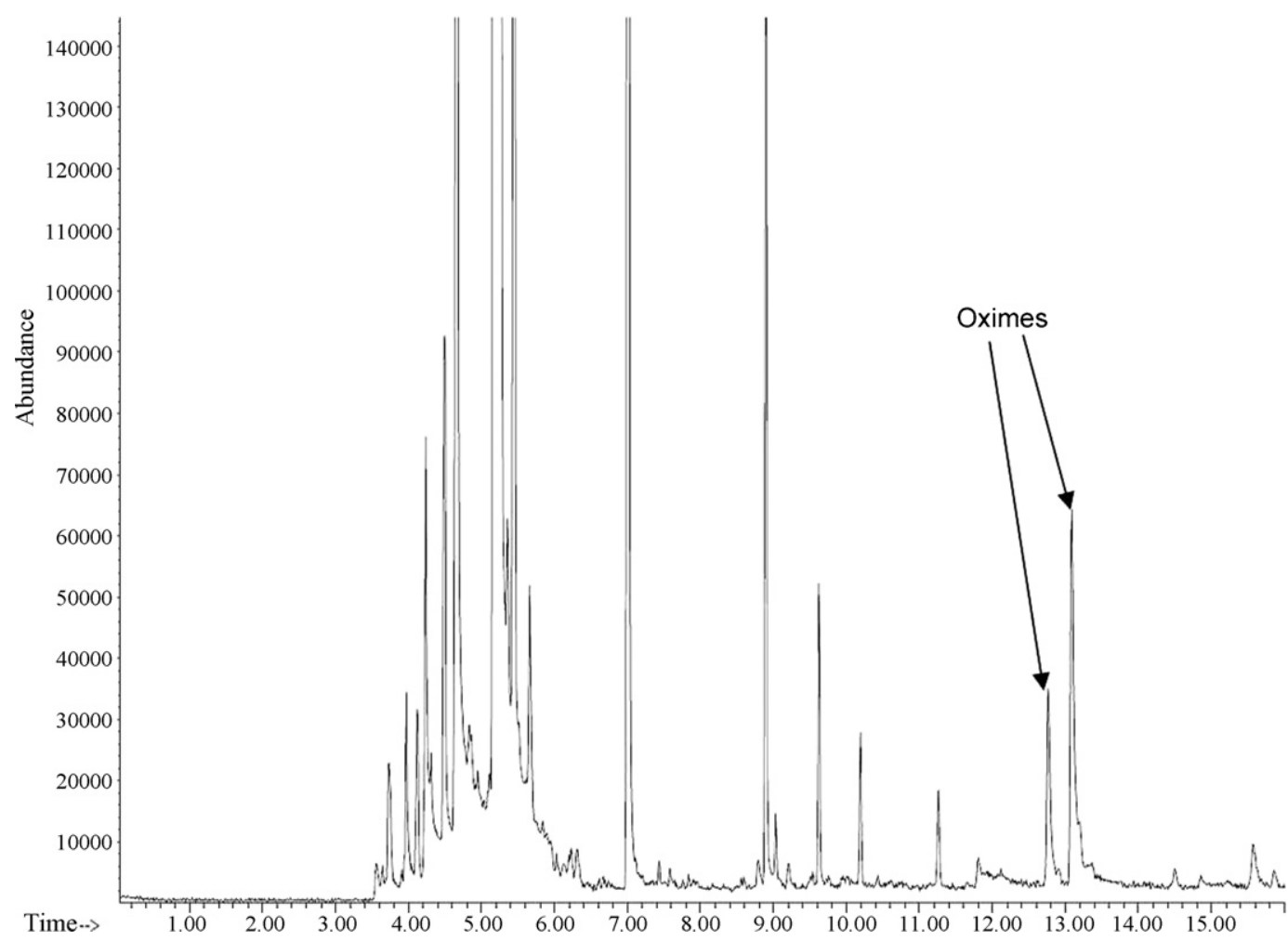

Fig. 3 - Chromatogram of sample injection. Oximes were formed on-fiber after the exposures of $784.3 \mu \mathrm{g} \mathrm{m}^{-3}$ ozone for $4 \mathrm{~h}$. GC/MS was used for the analysis.

the SPME diffusive sampler was exposed for various periods of time. As shown in Fig. 4, by plotting mass collected versus the magnitude of exposure (in concentration-time units), the experimental sampling rate of the sampler were deter-

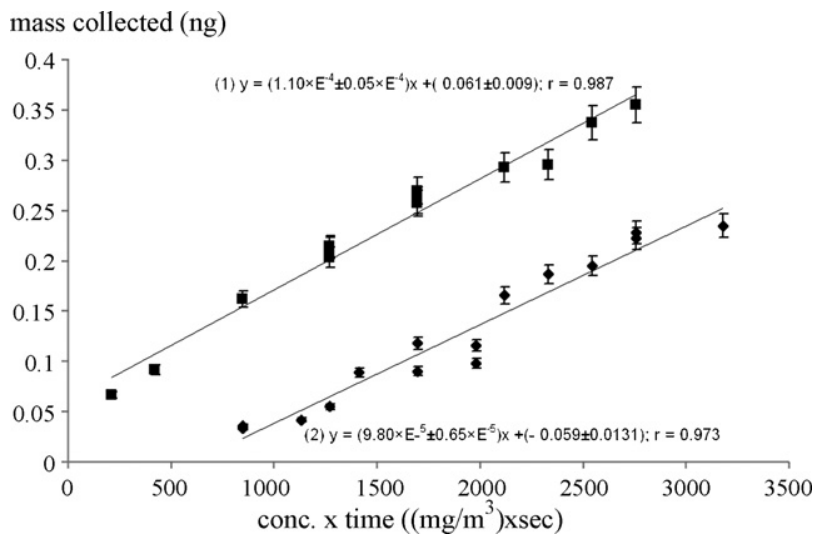

Fig. 4 - Ozone exposures from gas generation system. (1) Coating of PFBHA (headspace extraction of $17 \mathrm{mg} \mathrm{mL}^{-1}$ PFBHA solution for $1 \mathrm{~min}$ ) onto fiber was first performed followed by the direct immersion of DPE solution $\left(0.2 \mathrm{mg} \mathrm{mL}^{-1}\right.$ for $\left.30 \mathrm{~s}\right)$ for the preparation of trapping element; SPME fiber was directly injected into GC for analysis after sampling. (2) SPME fiber was loaded with DPE $\left(0.2 \mathrm{mg} \mathrm{mL}^{-1}\right.$ for $\left.30 \mathrm{~s}\right)$ by direct immersion for the preparation of trapping element; after sampling, headspace extraction of $17 \mathrm{mg} \mathrm{mL}^{-1}$ PFBHA solution for $20 \mathrm{~min}$ was then performed before the analysis with GC.
Table 2 - Stability tests of pyridin-4-aldehyde extracted on-fiber

\begin{tabular}{lcc} 
Storage condition $^{\mathrm{a}}$ & Relative peak areas $^{\mathrm{b}}$ & ${\text { Recovery }(\%)^{\mathrm{c}}}^{\mathrm{c}}$ \\
\hline None & $2999(n=3)$ & 100 \\
1 day & $2478(n=3)$ & 82.6 \\
4 days & $2160(n=3)$ & 72.0 \\
\hline
\end{tabular}

a Pyridine-4-aldehyde was extracted onto fiber by headspace extraction of $5 \mathrm{mg} \mathrm{mL}^{-1}$ pyridine-4-aldehyde solution for $1 \mathrm{~min}$ then the fibers were stored at $4^{\circ} \mathrm{C}$.

b PFBHA was further loaded onto fiber (headspace extraction for 2 min with PFBHA solution of $17 \mathrm{mg} \mathrm{mL}^{-1}$ ) to form oximes before the analysis with GC/MS; all the peak areas were shown as mean with $n=3$ and C.V. $<10 \%$.

c Compared with none storage condition.

mined to be $(1.10 \pm 0.05) \times 10^{-4}$ and $(98 \pm 6.5) \times 10^{-6} \mathrm{~cm}^{3} \mathrm{~s}^{-1}$, respectively. Further statistical analysis on the slopes showed significant differences for the sampling rate between these two approaches $(p<0.05)$.

The theoretical ozone sampling rate SR for the designed SPME device was $5.07 \times 10^{-4} \mathrm{~cm}^{3} \mathrm{~s}^{-1}$ while it was around five times higher than the experimental sampling rate found in this study. The inconsistencies between experimental and theoretical sampling rates for the SPME diffusive samplers have also been reported elsewhere [22,31,32]. Since the theoretical estimation could lead to great errors, experimental calibration of the sampling rate is then a must.

Fig. 4 also showed the linear ranges of sample collections from two different procedures of trapping element prepara- 
Table 3 - Comparisons of different passive sampling methods for ambient ozone

\begin{tabular}{|c|c|c|c|}
\hline Sampling reagent & Instrument used & Detection limits & Ref. \\
\hline DPE \& PFBHA & GC-ECD & $58.8 \mu \mathrm{g} \mathrm{m}^{-3} \mathrm{~h}^{\mathrm{a}}$ & Current study \\
\hline DPE \& MBTH & Spectrophotometry at $422 \mathrm{~nm}$ & $503.9 \mu \mathrm{g} \mathrm{m}^{-3} \mathrm{~h}\left(3 \mu \mathrm{g} \mathrm{m}^{-3}\right.$ week $)$ & [2] \\
\hline Indigo carmine & Spectrophotometry at $408 \mathrm{~nm}$ & $941.2 \mu \mathrm{g} \mathrm{m}^{-3} \mathrm{~h}\left(58.8 \mu \mathrm{g} \mathrm{m}^{-3}\right.$ day $)$ & [13] \\
\hline Nylon- 6 polymer \& potassium iodide & Coulometry & $784.3 \mu \mathrm{g} \mathrm{m}^{-3} \mathrm{~h}$ & [18] \\
\hline Nitrite ion & Ion chromatography & $394.1 \mu \mathrm{g} \mathrm{m}^{-3} \mathrm{~h}^{\mathrm{b}}\left(15.7 \mu \mathrm{g} \mathrm{m}^{-3}\right.$ day $)$ & [19] \\
\hline
\end{tabular}

tions. The lowest amount of oximes detected in the linear range from the procedure, coating of PFBHA onto the fiber for the preparation of trapping element first followed by the loading of DPE, was obtained from sampling at $705.8 \mu \mathrm{g} \mathrm{m}^{-3}$ for $5 \mathrm{~min}$. Therefore the detection limit can be down to $58.8 \mu \mathrm{g} \mathrm{m}^{-3}$ when the sampling time is $60 \mathrm{~min}$ (an hour). On the other hand, the detection limit would be $235.3 \mu \mathrm{g} \mathrm{m}^{-3} \mathrm{~h}^{-1}$ if only DPE was loaded onto fiber for ozone sampling, and PFBHA was loaded afterwards for further derivatizations before the analysis. It was observed that the procedure, coating of PFBHA onto the fiber for the preparation of trapping element first followed by the loading of DPE, will provide higher sampling rate and lower detection limit. Besides, the procedure was less time-consuming as well.

As shown in Table 2, the stability of pyridine-4-aldehyde on-fiber was tested in this study. It was observed that the recovery dropped to $82.6 \%$ after 1 -day storage at $4{ }^{\circ} \mathrm{C}$ while only $72 \%$ was recovered after 4 days. On the other hand, it has been reported that the stability of oximes formed on-fiber showed the recovery of $94 \%$ after 7 days of storage at $4{ }^{\circ} \mathrm{C}$ [32]. The results suggested that the procedure, coating of PFBHA onto the fiber for the preparation of trapping element first followed by the loading of DPE, will provide not only higher sampling rate, lower detection limits, but also better sample stability.

The side-by-side comparisons in the field between the SPME device and the Aeroqual Series 500 Ozone Monitor were performed in the study. To calculate the average concentrations of ozone that were sampled, $1.10 \times 10^{-4} \mathrm{~cm}^{3} \mathrm{~s}^{-1}$ was used as the experimental sampling constant of the SPME device. The correlation was linear with $r=0.9837$ by plotting the results from the Aeroqual Series 500 Ozone Monitor versus the results from the SPME devices. Therefore it was suggested that the results from both methods were consistent.

Several passive sampling methods for ozone can be found from literatures which used various reagents, as mentioned previously $[2,13-17,19]$. However, these methods all involved complex procedures for sample preparations (solvent desorption, for example) and therefore were very time-consuming, not to mention the limited-sensitivities (Table 3). On the other hand, the sampler designed in this research omits cumbersome procedure for the sample preparation while also provides better sensitivity because the SPME device with the sample analysis by GC-ECD was applied.

\section{Conclusions}

The diffusive sampling with the SPME device has an advantage over other methods because no pumps and solvents are required which reduces the sampling costs and the time for sample analysis. The research shown here extended the newly designed user-friendly sampling device to the validation of ozone sampling which will increase the wearer's acceptance.

Various derivatization techniques can be implemented combined with SPME, including direct derivatization in sample matrix, derivatization in GC injector port, and derivatization on SPME fiber coating. The analysis of ozone by GC-ECD and SPME with on-fiber derivatization technique was used in current research while provided acceptable sensitivity with simple and fast procedures. When compared with other methods, the cumbersome procedure such as solvent desorption was omitted obviously.

PDMS/DVB fiber with $1 \mathrm{~min}$ headspace extraction of $17 \mathrm{mg} \mathrm{mL}^{-1}$ PFBHA solution followed by $30 \mathrm{~s}$ direct immersion of $0.2 \mathrm{mg} \mathrm{mL}^{-1}$ DPE solution provided sufficient amounts of reagents needed for ozone sampling. The on-fiber derivatizations also increased the sample stability. However, the theoretical estimation of the sampling rate could lead to great errors and experimental calibration is a must.

\section{Acknowledgement}

This study was supported by grant from the National Science Council, Executive Yuan, Taiwan (NSC 95-2314-B-002-329).

\section{REFERE N C E S}

[1] M. Lippmann, JAPCA 39 (1989) 672.

[2] C. Monn, M. Hangartner, J. Air Waste Manage. Assoc. 40 (1990) 357.

[3] T.M. Chen, J. Gokhale, S. Shofer, W.G. Kuschner, Am. J. Med. Sci. 333 (2007) 244.

[4] N. Uysal, R.M. Schapira, Curr. Opin. Pulm. Med. 9 (2003) 144.

[5] C.C. Chan, T.H. Wu, Environ. Health Perspect. 113 (2005) 735.

[6] S.K. Rastogi, B.N. Gupta, T. Husain, H. Chandra, N. Mathur, B.S. Pangtey, S.V. Chandra, N. Garg, Am. J. Ind. Med. 20 (1991) 391.

[7] I.B. Tager, J. Balmes, F. Lurmann, L. Ngo, S. Alcorn, N. Künzli, Epidemiology 16 (2005) 751.

[8] R.Z. Sokol, P. Kraft, I.M. Fowler, R. Mamet, E. Kim, K.T. Berhane, Environ. Health Perspect. 114 (2006) 360.

[9] M.L. Bell, R. Goldberg, C. Hogrefe, P.L. Kinney, K. Knowlton, B. Lynn, J. Rosenthal, C. Rosenzweig, J.A. Patz, Climatic Change 82 (2007) 61.

[10] US Environmental Protection Agency: The ozone report, measuring progress through 2003. USEPA, Research Triangle Park, North Carolina, EPA454/K-04-001, 2004. 
[11] J. Fiala, L. Cernikovsky, F. de Leeuw, P. Kurfuerst, Air Pollution by Ozone in Europe in Summer 2003. Overview of Exceedances of EC Ozone Threshold Values During the Summer Season April-August 2003 and Comparison with Previous Years. European Environmental Agency, Copenhagen, EEA Topic Report 3/2003.

[12] M.J. Sanz, V. Calatayud, G. Sánchez-Peña, Environ. Pollut. 145 (2007) 620.

[13] D. Grosjean, M.W.M. Hisham, J. Air Waste Manage. Assoc. 42 (1992) 169.

[14] T.R. Hauser, D.W. Bradley, Anal. Chem. 38 (1966) 1529.

[15] M. Hangartner, M. Kirchner, H. Werner, Analyst 121 (1996) 1269.

[16] J. Zhou, S. Smith, J. Air Waste Manage. Assoc. 47 (1997) 697.

[17] A.C. Franklin, L.G. Salmon, J.M. Wolfson, C.S. Christoforou, J. Air Waste Manage. Assoc. 54 (2004) 1312.

[18] Y. Yanagisawa, Res. Rep. Health Eff. Inst. 63 (1994) 49.

[19] P. Koutrakis, J.M. Wolfson, A. Bunyaviroch, S.E. Froehlich, K. Hirano, J.D. Mulik, Anal. Chem. 65 (1993) 209.

[20] R. Otson, P. Fellin, Sci. Total Environ. 77 (1988) 95.

[21] M.L. Bao, F. Pantani, O. Griffini, D. Burrini, D. Santianni, K. Barbieri, J. Chromatogr. A 809 (1998) 75.
[22] S.W. Tsai, T.A. Chang, J. Chromatogr. A 954 (2002) 191.

[23] S.W. Tsai, C.M. Chang, J. Chromatogr. A 1015 (2003) 143.

[24] J. Pawliszyn, Solid Phase Microextraction-Theory and Practice, Wiley-VCH, New York, 1997.

[25] J. Pawliszyn, Application of Solid Phase Microextraction, Royal Society of Chemistry, Cambridge, 1999.

[26] J.A. Koziel, J. Pawliszyn, J. Air Waste Manage. Assoc. 51 (2001) 173.

[27] A. Khaled, J. Pawliszyn, J. Chromatogr. A 892 (2000)455.

[28] P.A. Martos, J. Pawliszyn, Anal. Chem. 70 (1998) 2311.

[29] P.A. Martos, J. Pawliszyn, Anal. Chem. 71 (1999) 1513.

[30] R. Batlle, A. Colmsjo, U. Fresenius, J. Anal. Chem. 371 (2001) 514.

[31] S.W. Tsai, K.K. Wu, J. Chromatogr. A 991 (2003) 1.

[32] S.W. Tsai, K.Y. Kao, J. Chromatogr. A 1129 (2006) 29.

[33] R.C. Reid, J.M. Prausnitz, B.E. Poling (Eds.), The Properties of Gases and Liquids, fourth ed., McGraw-Hill, New York, 1988, p. 586.

[34] G. Jakobi, P. Fabian, Indoor outdoor concentrations of ozone and peroxyacetyl nitrate (PAN), Int. J. Biometeorol. 40 (1997) 162.

[35] D.A. Cancilla, S.S. Que Hee, J. Chromatogr. 627 (1992) 1. 